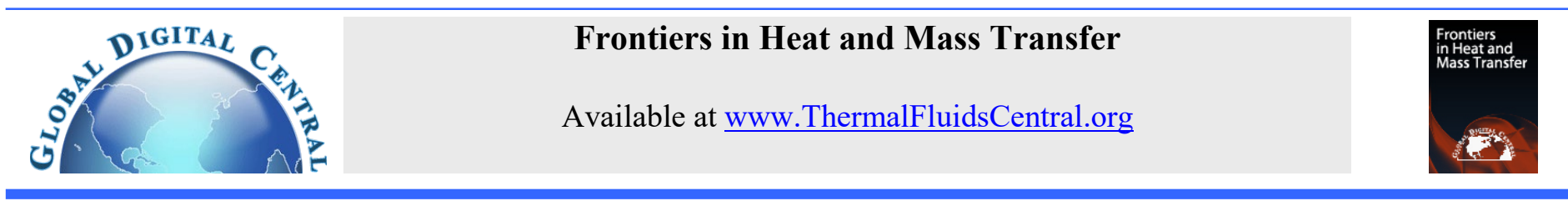

\title{
A STUDY ON MHD BOUNDARY LAYER FLOW ROTATING FRAME NANOFLUID WITH CHEMICAL REACTION
}

\author{
N. Vedavathi ${ }^{\mathrm{a}}$, G. Dharmaiah ${ }^{\mathrm{b} *}$, K.S. Balamurugan ${ }^{\mathrm{c}}$, and K. Ramakrishna ${ }^{\mathrm{d}}$ \\ ${ }^{a}$ Department of Mathematics, Koneru Lakshmaiah Education Foundation, Vaddeswaram, Guntur, Andhra Pradesh, 522502, India. \\ ${ }^{b}$ Department of Mathematics, Narasaraopeta Engineering College, Yellamanda, Narsaraopet, Andhra Pradesh, 522601, India. \\ ${ }^{c}$ Department of Mathematics, RVR \& JC College of Engineering, Chowdavaram, Guntur, Andhra Pradesh, 522019, India. \\ ${ }^{d}$ Department of Mechanical Engineering, Koneru Lakshmaiah Education Foundation, Vaddeswaram, Guntur, Andhra Pradesh, 522502, \\ India.
}

\begin{abstract}
The effect of chemical reaction on MHD free convection heat transfer flow of a nanofluid bounded a semi-infinite flat surface in a rotating frame of reference is theoretically investigated. The velocity along the plate (slip velocity) is assumed to oscillate on time with constant frequency. The analytical solutions of different water based nanofluids containing $\mathrm{TiO}_{2}, \mathrm{Al}_{2} \mathrm{O}_{3}, \mathrm{Ag}, \mathrm{Cu}$ and $\mathrm{CuO}$ of the boundary layers are assumed, to keep the problem as realistic as possible. The dimensionless governing equations for this investigation are solved analytically by using the small perturbation Technique. The effects of various physical parameters on velocity, temperature and concentration fields are presented graphically. The enhancement in magnetic parameter leads to a considerable reduction in velocity and chemical reaction parameter is predominant in controlling the concentration profile. The results obtained in the simulation of perturbation method are in well agreement with realistic situation of the scientific scenario.
\end{abstract}

Keywords: Chemical reaction, water based nano-fluids, Rotating frame, constant heat source.

\section{INTRODUCTION}

The idea of nanofluid isn't new as in 1857 Michael Faraday initially announced the examination on the combination and shades of colloidal gold. The blend of suspended nanoparticles in a base fluid is typically alluded to as a nanofluid. Nature is brimming with nanofluids, similar to blood, a complex organic nanofluid where distinctive nanoparticles (at atomic dimension) achieve diverse capacities, and utilitarian parts effectively react to their neighborhood condition. As indicated by the sorts of fluids (natural and inorganic) and sorts of nanoparticles, one can get distinctive kinds of nanofluids like process extraction nanofluids, ecological (contamination controlling nanofluids), bio-, and pharmaceutical nanofluids. Another class of polymer nanofluids, dragdiminishing nanofluids, go for improved heat exchange, and in addition, stream grinding decrease. An extensive variety of dynamic self-get together systems for nanoscale structures begin from a suspension of nanoparticles in liquid. Present day nanotechnology enables one to process and deliver materials with normal crystallite estimate $<50 \mathrm{~nm}$. Nanofluid have someone of a kind highlights that are very not quite the same as regular two-stage stream blends in which $\mu \mathrm{m}$ as well as mm particles are suspended. Contrasted with a regular fluid and traditional two-stage blend, the nanofluid has higher thermal conductivity, does not square stream channels, and initiates a little weight drop. Strong particles are included as they lead warm much superior to a fluid. Furthermore, nanoparticles oppose sedimentation, when contrasted with bigger particles, because of Brownian movement and interparticle powers and have a lot higher surface zone (1,000-time) which improves the heat conduction of nanofluids since heat exchange happens on the surface of the liquid. Three properties that make nanofluids promising coolants are: (i) expanded heat conductivity,(ii) expanded single-stage heat exchange, and (iii) expanded basic heat motion. Research has demonstrated that generally little measures of nanoparticles, of the request of 5 Vol. percent or less, can upgrade thermal conductivity of the base liquid to a huge degree. Along these lines, abusing the extraordinary qualities of nanoparticles, nanofluids are made with two highlights essential for heat exchange systems:(i) outrageous strength, and (ii) ultra-high thermal conductivity. The ongoing research ever since then has extended to utilization of nanofluids in microelectronics, fuel cells, pharmaceutical processes, hybridpowered engines, engine cooling, vehicle thermal management, domestic refrigerator, chillers, heat exchanger, nuclear reactor coolant, grinding, machining, space technology, defense and ships, and boiler flue gas temperature reduction.

A rotating frame of reference is used to model flows in rotating machines. In these cases, the flow is unsteady in an inertial frame (nonaccelerating coordinate system in the inertial frame) because the blades or rotors sweep the domain periodically. However, it is possible to perform the calculations in a domain that moves with the rotating coordinate which is fixed on the rotating part. In this approach, the flow is steady relative to the rotating (non-inertial) frame, which reduces the expensive computations needed for an accurate analysis. This approach is appropriate when the flow at the boundary between the rotating parts and the stationary parts is weakly affected by the interaction. It provides a reasonable time-averaged simulation result for many applications. Rotating frames don't physically rotate anything and therefore do not show transient effects due to the real motion. Instead, a quasi-steady state solution is calculated due to the rotating equipment. Any problems where transient effects due to rotor-stator interaction are small are candidates to use the rotating frame of reference approach. A typical example is the mixing tank where the impeller-baffle interactions are

\footnotetext{
*Corresponding Author: dharma.g2007@gmail.com
} 
relatively weak; large-scale transient effects are not present. The study of fluid flow due to a rotating frame has become increasingly popular in fluid dynamic research for the interest not only practical but also academic. The flow over a rotating frame is important because of its wide applications in many engineering, industrial, geothermal, geophysical, and technological fields.

In the last few years, the dynamical study of non-Newtonian fluids has got vital attention among various researchers. The flow produced from these type of fluids can be used to analyze a broader class of fluids that exist in the physical world. The distinctive property of nonNewtonian fluids is to have the variable viscosity. Non-Newtonian fluids are rheologically complex fluids represented by the non-linear relationships among shear stress and strain rate. The micropolar fluid model, also known as polar fluid, is one of the non-Newtonian models that have microstructure. Micropolar fluids come into the category of fluids that have nonsymmetrical stress tensor and consist of stiff and arbitrarily structured particles hanging in a viscous channel where the deformation of fluid particles is uncountable. In recent times, a lot of researchers have been giving their attention to the theory of micropolar fluids and this is because conventional Newtonian fluids does not have the ability to explain the properties of the fluid flows containing suspended particles. The main reason for the significant attention to the investigation of the flows of micropolar fluids was their usages and applications in different industrial processes, which include: solidification of liquid crystal, the extrusion of polymer fluids, animal blood, exotic lubricants, cooling of a metallic plate in a bath, and colloidal and suspension solutions. More complex fluids can be described by the extension of Newtonian fluids to the theory of micropolar fluid flow.

The thermal conductivity of solid metals is larger than fluids; therefore suspending these particles can increase thermal conductivity and heat transfer performance. Thermal radiation is important in some applications because of the manner in which radiant emission depends on temperature and nanoparticles volume fraction. The thermal radiation effect on mixed convection heat transfer in porous media has many important applications such as the sensible heat storage bed, the nuclear reactor cooling system, space technology, and underground nuclear waste disposal. Several studies have been conducted this field as presented by Choi and Eastman (1995) experimentally and numerically (e.g., Rasidi et al., 2015; Rashidi et al., 2014). Makinde and Aziz (2011) examined on boundary layer flow this is propagated in a nanofluid due to linearly stretching sheet. Thermal radiation has prospective role in manufacturing design of nuclear power plants and various engineering processes. Several researchers have paid their interest to address the mechanism of thermal radiation. Hayat et al., (2015) analyzed in their studies the mixed convection flow of nonnewtonian nanofluid in the presence of thermal radiation, heat source/sink and first order chemical reaction. Buongiorno (2005) performed the flow characteristics of viscous, with incompressible fluids with suspended nano-sized solid particles high significant due to the application of such fluids in heat transfer devices. Xie et al. (2010) explained magnesium oxide nanofluids; higher thermal conductivity and lower viscosity with ethylene glycol-based nanofluids containing oxide nanoparticles. The existing literature was shown that ensures the enlargement of nanoparticles in the base fluid may bring about an essentially reducing in the heat transfer; for comprehensive review, see (Kakac and Pramuanjaroenkij (2009), Sheikholeslami et al. (2014)). Rushi Kumar et al. (2015) presented on unsteady free convection flow in the occurrence of magnetic field fixed relative to the fluid or the plate. Nadeem et al. (2014) examined the steady flow of a Casson fluid in the presence of nanoparticles. Heat and mass transfer in MHD nonNewtonian flow were numerically analyzed by Raju and Sandeep (2016). Tawade et al. (2016) studied the unsteady flow and heat transfer of thin film over a stretching surface in the presence of thermal radiation. Hydromagnetic phenomena are outcome of mutual interaction between magnetic field and electrically conducting fluid flowing across it. The behavior of an electrically conducting fluid with electromagnetic field has applications in many different fields of engineering as well as geophysics, astrophysics, technological and industrial manufacturing. This concerns the production of synthetic sheets, aerodynamic extrusion of plastic sheets, cooling of metallic plates, etc. In recent year, several researchers studied the nanofluid boundary layer flow with various physical effects in the occurrence of magnetic field. (Hamad, 2011; Rashidi et al., 2014; Malvandi et al.,2014; Sheikholeslami et al.,2014; Ellahi et al., 2015; Ellahi et al., 2015; Noreen et al., 2015). Further, Sandeep (2016) and Ramana Reddy et al. (2017) considered the heat transfer behaviour of MHD flows. The study of MHD flow and heat transfer due to the effect of a magnetic field in a rotating frame of reference has attracted the interest of many investigators in view of its applications in many industrial, astrophysical (dealing with the sunspot development, the solar cycle and the structure of a rotating magnetic stars), technological and engineering applications (MHD generators, ion propulsion, MHD pumps, etc.) and many other practical applications, such as in biomechanical problems (e.g., blood, flow in the pulmonary alveolar sheet). Many authors have studied the flow and heat transfer in a rotating system with various geometrical situations (2011). Hamad (2011) investigated the effect of a transverse magnetic field on free convection flow of a nanofluid past a vertical semi infinite flat plate. Recently, Satya Narayana et al. (2013) studied the Hall current and radiation absorption effects on MHD micropolar fluid in a rotating system. Some other related works can also be found in recent papers (2012).

Motivated by the aforementioned work and its applications in various fields of science and technology, it is of interest to discuss and analyze the heat source and radiation effects on the free convection heat and mass transfer flow of nanofluid over a vertical plate. An objective of the paper is to study only on micropolar fluid flow over a rotating the effect of chemical reaction on MHD free convection heat transfer flow of a nanofluid bounded by a semi-infinite flat surface is theoretically investigated. The velocity along the plate (slip velocity) is assumed to oscillate on time with a constant frequency. The analytical solutions of different water-based nanofluids containing $\mathrm{TiO}_{2}, \mathrm{Al}_{2} \mathrm{O}_{3}, \mathrm{Ag}, \mathrm{Cu}$ and $\mathrm{CuO}$ of the boundary layer equations are assumed, of oscillatory type and are obtained by using the small perturbation approximations. The influence of various relevant physical characteristics are presented and discussed.

\section{ANALYSIS OF THE FLOW OF THE PROBLEM}

This paper we consider an unsteady three-dimensional flow of an electrically conducting incompressible nanofluid past a semi-infinite vertical permeable plate with radiation and heat absorption. A uniform external magnetic field $\mathrm{B}_{0}$ is taken to be acting along the $\mathrm{z}^{*}$ axis. It is assumed that there is no applied voltage which implies the absence of an electric field. The flow is assumed to be in the $\mathrm{x}^{*}$ - direction which is taken along the plate in the upward direction and $\mathrm{z}^{*}$ axis is normal to the plate (see Fig. 1). Also it is assumed the whole system is rotated with a constant vector $\Omega$ about the $\mathrm{z}^{*}$-axis. The fluid is grey, absorbing emitting but not scattering medium. The radiation heat flux in $x_{*}^{*}$ direction is considered negligible in comparison that in the $\mathrm{z}^{*}$ direction. Due to semi-infinite plate surface assumption the flow variables are functions of $\mathrm{z}$ and time $\mathrm{t}$ only.

Assumed that the regular fluid and the suspended nano particles are in thermal equilibrium and no slip occurs between them. Boundary layer approximations, the boundary layer equations governing the flow, temperature and concentration along with the Boussinesq are:

$$
\begin{aligned}
& \frac{\partial w^{*}}{\partial z^{*}}=0 \\
& \frac{\partial u^{*}}{\partial t^{*}}+w^{*} \frac{\partial u^{*}}{\partial z^{*}}-2 \Omega v^{*}=\frac{\mu_{n f}}{\rho_{n f}} \frac{\partial^{2} u^{*}}{\partial z^{2}}+\frac{[\rho \beta]_{n f}}{\rho_{n f}} g\left(T-T_{\infty}\right)-\frac{1}{\rho_{n f}} \sigma B_{0}^{2} u^{*}
\end{aligned}
$$




$$
\begin{aligned}
& \frac{\partial v^{*}}{\partial t^{*}}+w^{*} \frac{\partial v^{*}}{\partial z^{*}}+2 \Omega u^{*}=\frac{\mu_{n f}}{\rho_{n f}} \frac{\partial^{2} v^{*}}{\partial z^{2}}-\frac{1}{\rho_{n f}} \sigma B_{0}^{2} v^{*} \\
& \frac{\partial T}{\partial t^{*}}+w^{*} \frac{\partial T}{\partial t^{*}}=\alpha_{n f} \frac{\partial^{2} T}{\partial z^{2}}-\frac{1}{[\rho C p]_{n f}}\left[Q^{*}\left(T-T_{\infty}\right)+\frac{\partial q_{r}}{\partial z^{*}}\right]+Q_{1}^{*}\left(C-C_{\infty}\right) \\
& \frac{\partial C}{\partial t^{*}}+w^{*} \frac{\partial C}{\partial z^{*}}=D^{*} \frac{\partial^{2} C}{\partial z^{2}}-K_{1}^{*}\left(C-C_{\infty}\right)
\end{aligned}
$$

The boundary conditions for the problem are given by

$u^{*}\left(z^{*}, t^{*}\right)=0, v^{*}\left(z^{*}, t^{*}\right)=0, T=T_{\infty}, C=C_{\infty} \quad$ for $t^{*} \leq 0$ and any $z^{*}$

$u^{*}\left(\infty, t^{*}\right)=U_{0}\left[1+\frac{\varepsilon}{2}\left(e^{\mathrm{in} * \mathrm{t}^{*}}+e^{-\mathrm{in} * \mathrm{t}^{*}}\right)\right]$,

$T\left(\infty, t^{*}\right) \rightarrow T_{\infty}, C\left(\infty, t^{*}\right) \rightarrow C_{\infty}$ for $t^{*} \geq 0$

Here $\mathrm{u}^{*}, \mathrm{v}^{*}$ and $\mathrm{w}^{*}$ are the velocity components along the $\mathrm{x}^{*}, \mathrm{y}^{*}$ and $\mathrm{z}^{*}$ axis respectively. The properties of nanofluids which are given by [Oztop and Abu-Nada (2008)]

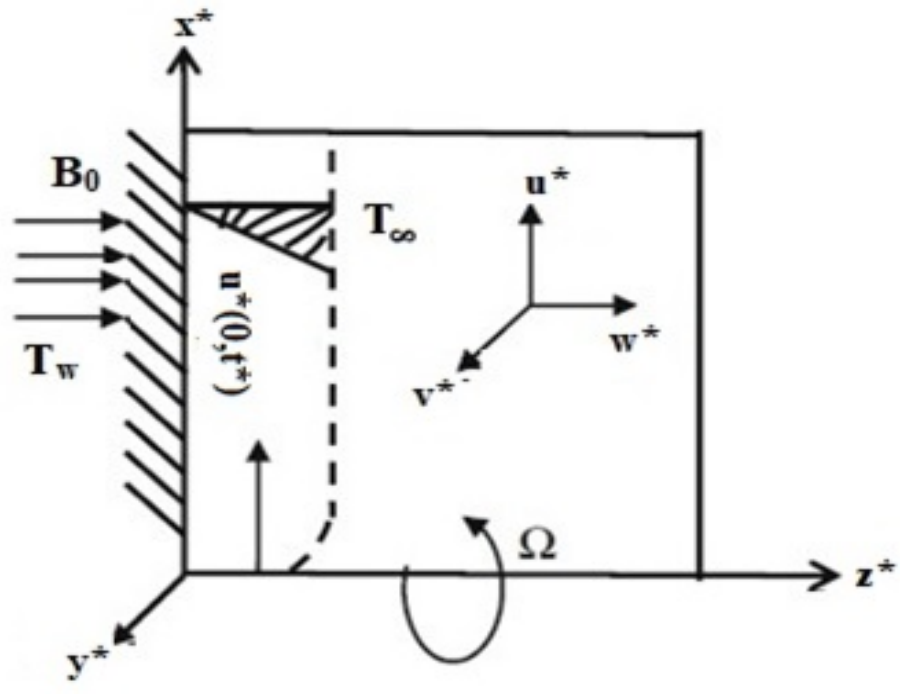

Fig. 1 Physical Model of the problem

$\rho_{n f}=(1-\phi) \rho_{f}+\phi \rho_{s}$,

$(\rho C p)_{n f}=(1-\phi)(\rho C p)_{f}+\phi(\rho C p)_{s}$,

$(\rho \beta)_{n f}=(1-\phi)(\rho \beta)_{f}+\phi(\rho \beta)_{s}$,

$\mu_{n f}=\frac{\mu_{f}}{[1-\phi]^{2.5}}$

$\alpha_{n f}=\frac{K_{n f}}{(\rho C p)_{n f}}$,

$\frac{K_{n f}}{K_{f}}=\left[\frac{K_{s}+2 K_{f}-2 \phi\left(K_{f}-K_{s}\right)}{K_{s}+2 K_{f}+2 \phi\left(K_{f}-K_{s}\right)}\right]$

By using the Rosseland approximation, the radiative flux vector $q_{r}$ can be written as:

$q_{r}^{*}=-\frac{4 \sigma^{*}}{3 k_{1}^{\prime}} \frac{\partial T_{w}^{* 4}}{\partial z}$

Where, $\sigma^{*}$ and $k_{1}^{*}$ are respectively the Stefan-Boltzmann constant and the mean absorption coefficient.
The thermo physical properties of the base fluid (water) and other nanofluids are shown in Table 1.

Table. 1 Nano fluids and their thermo physical Characteristics (Turkyilmanzoglu[2016])

\begin{tabular}{|c|c|c|c|c|}
\hline Nanofluids & Density $(\rho)$ & $\begin{array}{c}\text { Specific } \\
\text { Heat }(\mathrm{Cp})\end{array}$ & $\begin{array}{c}\text { Thermal } \\
\text { Conductivity(k) }\end{array}$ & $\beta \mathrm{X} 10^{-5}$ \\
\hline $\begin{array}{c}\text { Titanium } \\
\text { Oxide }\left(\mathrm{TiO}_{2}\right)\end{array}$ & 4250 & 686.2 & 8.9538 & 0.9 \\
\hline Alumina $\left(\mathrm{Al}_{2} \mathrm{O}_{3}\right)$ & 3970 & 765 & 40 & 0.85 \\
\hline Silver $(\mathrm{Ag})$ & 10500 & 235 & 429 & 1.89 \\
\hline Copper $(\mathrm{Cu})$ & 8933 & 385 & 401 & 1.67 \\
\hline $\begin{array}{c}\text { Copper } \\
\text { Oxide }(\mathrm{CuO})\end{array}$ & 6320 & 531.8 & 76.5 & 1.80 \\
\hline Pure water & 997.1 & 4179 & 0.613 & 21 \\
\hline
\end{tabular}

We assume that the temperature difference within the flow is sufficiently small such that $T^{*}$ may be expressed as a linear function of the temperature. This is accomplished by expanding in a Taylor series about the free stream temperature $T_{\infty}^{*}$ and neglecting higher order terms, thus

$T_{w}^{*^{4}} \cong 4 T_{\infty}^{* 3} T_{w}^{*}-3 T_{\infty}^{* 4}$

The solution of Eq. (1) is considered as $w^{*}=-w_{0}$

Introducing dimensionless variables in the following manner:

$$
\begin{aligned}
& u=\frac{u^{*}}{U_{0}}, v=\frac{v^{*}}{U_{0}}, z=\frac{z^{*} U_{0}}{v_{f}}, t=\frac{t^{*} U_{0}^{2}}{v_{f}}, n=\frac{v_{f} n^{*}}{U_{0}^{2}}, \\
& S=\frac{w_{0}}{U_{0}}, R=\frac{2 \Omega v_{f}}{U_{0}^{2}}, Q_{H}=\frac{Q^{*} v_{f}^{2}}{K_{f} U_{0}^{2}}, \operatorname{Pr}=\frac{v_{f}(\rho C p)_{f}}{K_{f}} \\
& Q_{1}=\frac{Q_{1}^{*}\left(C_{w}-C_{\infty}\right)}{\left(T_{w}-T_{\infty}\right) U_{0}^{2}}, F=\frac{4 \sigma^{*} T_{\infty}^{3}}{k k_{1}^{*}}
\end{aligned}
$$

Substituting Eq. (12) into Eqs. (2) - (5) yields the following dimensionless equations:

$$
\begin{aligned}
& \frac{\partial u}{\partial t}-S \frac{\partial u}{\partial z}-R v=B_{1} \frac{\partial^{2} u}{\partial z^{2}}+B_{2} \theta-B_{3} u M \\
& \frac{\partial v}{\partial t}-S \frac{\partial v}{\partial z}+R u=B_{1} \frac{\partial^{2} v}{\partial z^{2}}-B_{3} v M \\
& \frac{\partial \theta}{\partial t}-S \frac{\partial \theta}{\partial z}=\frac{B_{4}}{\operatorname{Pr}} \frac{\partial^{2} \theta}{\partial z^{2}}-\frac{B_{5} Q_{H}}{\operatorname{Pr}} \theta+Q_{1} \psi \\
& \frac{\partial \psi}{\partial t}-S \frac{\partial \psi}{\partial z}=\frac{1}{S c} \frac{\partial^{2} \psi}{\partial z^{2}}-K r \psi
\end{aligned}
$$

where the corresponding boundary conditions (6) \& (7) can be written in the dimensionless form as:

$$
\begin{gathered}
u(z, t)=0, v(z, t)=0, \theta(z, t)=0, \psi(z, t)=0 \quad \text { for } t \leq 0 \text { and any } z \\
\left.\begin{array}{c}
u(0, t)=1+\frac{\varepsilon}{2}\left[e^{\text {int }}+e^{-\mathrm{int}}\right], v(0, t)=0, \theta(z, t)=1, \psi(z, t)=1 \\
u(\infty, t) \rightarrow 0, v(\infty, t) \rightarrow 0, \theta(\infty, t) \rightarrow 0, \psi(\infty, t) \rightarrow 0
\end{array}\right\} \text { for } t \geq 0
\end{gathered}
$$

Using Eq. (13) the velocity characteristic $\mathrm{U}_{0}$ is defined as $U_{0}=\sqrt[3]{g \beta_{f} v_{f}\left(T_{w}-T_{\infty}\right)}$

Now, in order to obtain the desired solutions of Eqs. (13) - (16), we assume that the fluid velocity in the complex form as:

$\chi(z, t)=u(z, t)+i v(z, t)$

By using Eq. (18) we can simplify Eqs. (13) and (14) to the following equation 


$$
\frac{\partial \chi}{\partial t}-S \frac{\partial \chi}{\partial z}-R v=B_{1} \frac{\partial^{2} \chi}{\partial z^{2}}+B_{2} \theta-B_{3} \chi M
$$

The boundary conditions (17) becomes

$$
\left.\begin{array}{c}
\chi(z, t)=0, \theta(z, t)=0, \psi(z, t)=0 \quad \text { for } t \leq 0 \text { and any } z \\
\chi(0, t)=1+\frac{\varepsilon}{2}\left[e^{\mathrm{int}}+e^{-\mathrm{int}}\right], \theta(z, t)=1, \psi(z, t)=1 \\
\chi(\infty, t) \rightarrow 0, \theta(\infty, t) \rightarrow 0, \psi(\infty, t) \rightarrow 0
\end{array}\right\} \text { for } t \geq 0
$$

To solve Eqs. (13)- (16) under the boundary conditions (17) in the neighborhood of the plate, we assume that (see Ganapathy [1994]).

$$
\begin{aligned}
& \chi(z, t)=\chi_{0}(z, t)+\frac{\varepsilon}{2}\left\{e^{\text {int }} \chi_{1}+e^{\text {int }} \chi_{2}\right\} \\
& \theta(z, t)=\theta_{0}(z, t)+\frac{\varepsilon}{2}\left\{e^{\text {int }} \theta_{1}+e^{\text {int }} \theta_{2}\right\} \\
& \psi(z, t)=\psi_{0}(z, t)+\frac{\varepsilon}{2}\left\{e^{\text {int }} \psi_{1}+e^{\text {int }} \psi_{2}\right\}
\end{aligned}
$$

Invoking the above Eqs. (21) - (23) into the Eqs. (13) - (16) with boundary conditions (17), we obtain the expression for velocity, temperature and concentration as:

$$
\begin{aligned}
& \chi(z, t)=W_{3} e^{-r_{1} z}+W_{4} e^{-r_{2} z}+W_{5} e^{-r_{3} z}+\frac{\varepsilon}{2}\left\{e^{-r_{4} z} e^{\text {int }}+e^{-r_{5} z} e^{- \text {int }}\right\} \\
& \theta(z, t)=W_{1} e^{-r_{1} z}+W_{2} e^{-r_{2} z} \\
& \psi(z, t)=e^{-\xi_{1} z}
\end{aligned}
$$

\section{RESULTS AND DISCUSSIONS}

A theoretical study on the effect of the metallic nanoparticle on MHD free convection flow along a vertical permeable semi-infinite flat plate with heat source when the plate oscillates in time $t$ in the presence of a rotating frame of reference has been performed in this paper. The effects of nanoparticles on the velocity, the temperature and concentration profiles. We have chosen here $\mathrm{n}=10, \mathrm{nt}=\pi / 2, \operatorname{Pr}=6.72$, $\varepsilon=0.02, \phi=0.10, \mathrm{Sc}=0.16, \mathrm{~F}=1, \mathrm{Q}_{1}=1, \mathrm{M}=0.5, \mathrm{R}=0.02, \mathrm{QH}_{\mathrm{H}}=10$ and $\mathrm{S}=1.5$ to draw graphs. The effects of chemical reaction parameter on velocity profiles for $\mathrm{TiO}_{2}, \mathrm{Al}_{2} \mathrm{O}_{3}, \mathrm{Ag}, \mathrm{Cu}$ and $\mathrm{CuO}$ are illustrated graphically through Fig. 2 . It is interesting to note that the velocity of nanofluid $\mathrm{Cu}$ is very high than the other nanofluids, as $\mathrm{Kr}$ is increasing. The figure shows the boundary layer will be thicker when the nanofluid $\mathrm{Cu}$ is accounted for. It is evident that momentum layer is redistributed as the nanoparticles vary from Cuo to $\mathrm{TiO}_{2}$. Figure 3 exhibits the behavior temperature profile for changing chemical reaction parameter $\mathrm{Kr}$. The figure shows that, as chemical reaction parameter is increasing, the temperature is more spread for the nanofluid $\mathrm{TiO}_{2}$. The adjusting feature of nanofluids on the thermal boundary thickness is apparent. Figure 4 presents typical profile for the nanofluid concentration profiles for different values of chemical reaction parameter $\mathrm{Kr}$. From the graph, it is obvious that the nanofluid concentration of the fluid decelerates with increase in the strength of concentration $\mathrm{Kr}$. The effects of suction parameter $\mathrm{S}$ on the dimensionless velocity is shown in Fig. 5. It is noticed that values of velocities for $\mathrm{TiO}_{2}$ nano particles are larger than $\mathrm{Al}_{2} \mathrm{O}_{3}, \mathrm{Ag}, \mathrm{Cu}$ and $\mathrm{CuO}$ nanoparticles and the hydro dynamic boundary layer decreases from $\mathrm{TiO}_{2}$ to $\mathrm{CuO}$ nanoparticles. The effects of suction parameter $\mathrm{S}$ on the dimensionless temperature are shown in Fig. 6. The thermal boundary layer decreases from $\mathrm{TiO}_{2}$ to $\mathrm{CuO}$ nanoparticles. Titanium oxide has the lowest thermal conductivity rather than other nanoparticles. The influence of suction parameter $\mathrm{S}$ on concentration profile is shown in Fig. 7. Concentration decreases with the increase in the suction parameter indicating that the nanoparticle volume fraction decreases with the increase of suction parameter. The influences of Schmidt number Sc on the dimensionless velocity is

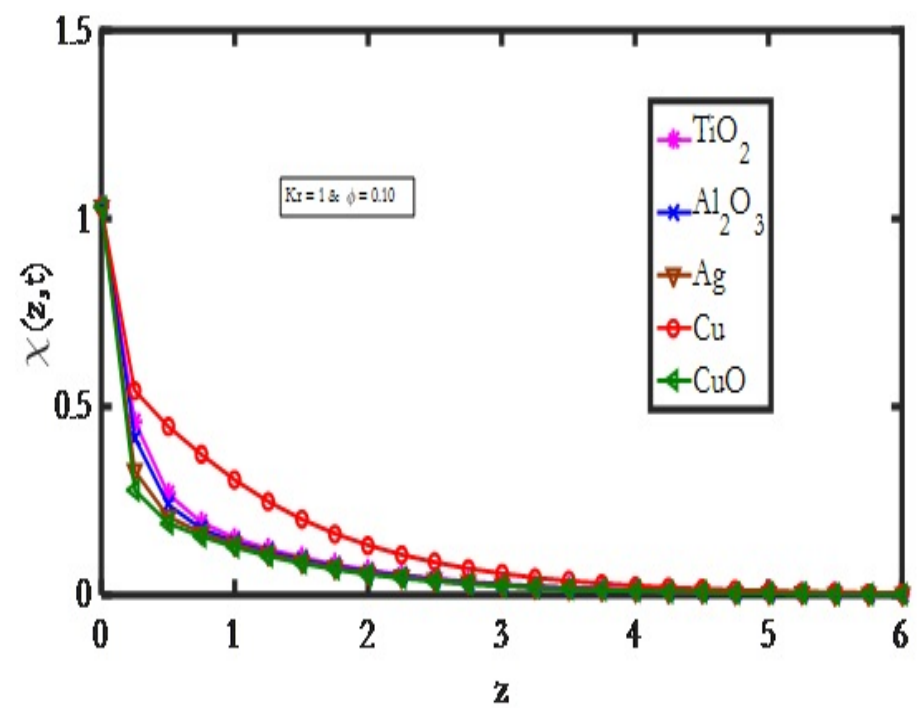

Fig. 2 The effect of Chemical reaction Parameter on velocity profiles.

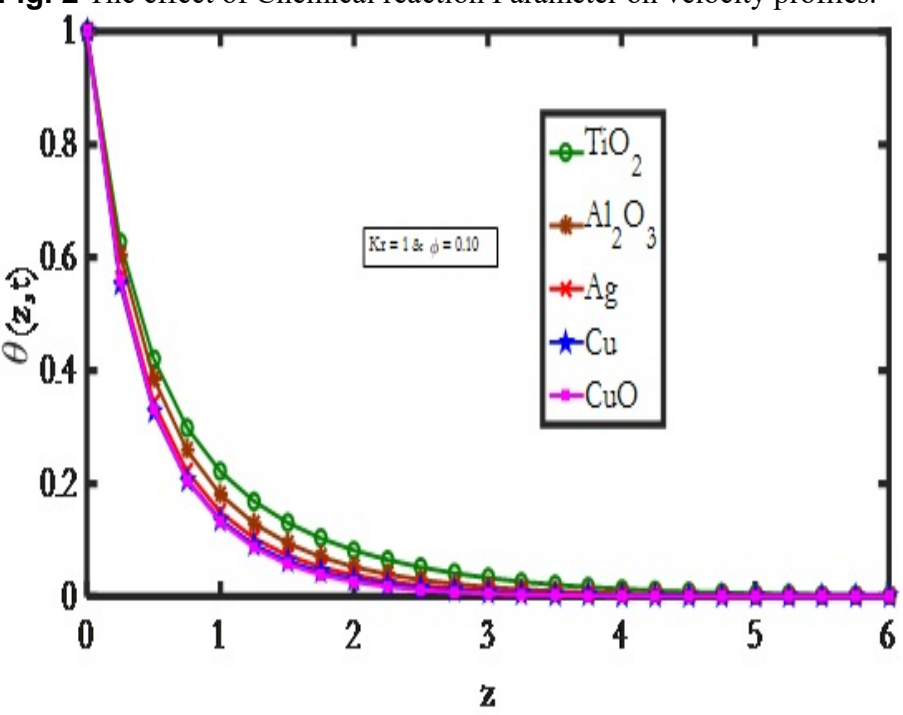

Fig. 3 The effect of Chemical reaction Parameter on temperature profiles.

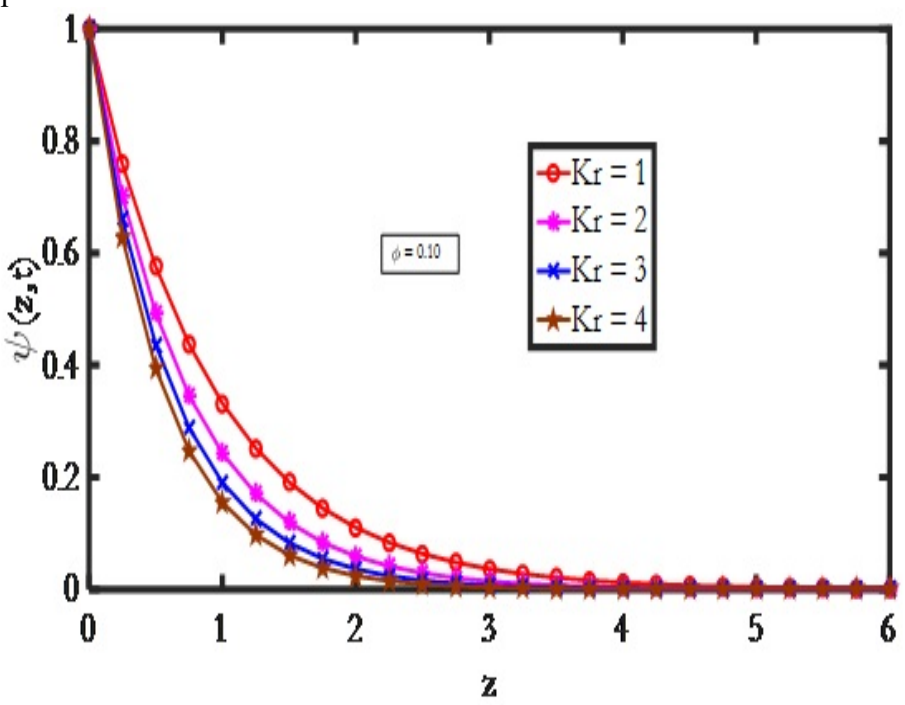

Fig. 4 The effect of Chemical reaction Parameter on concentration profiles. 


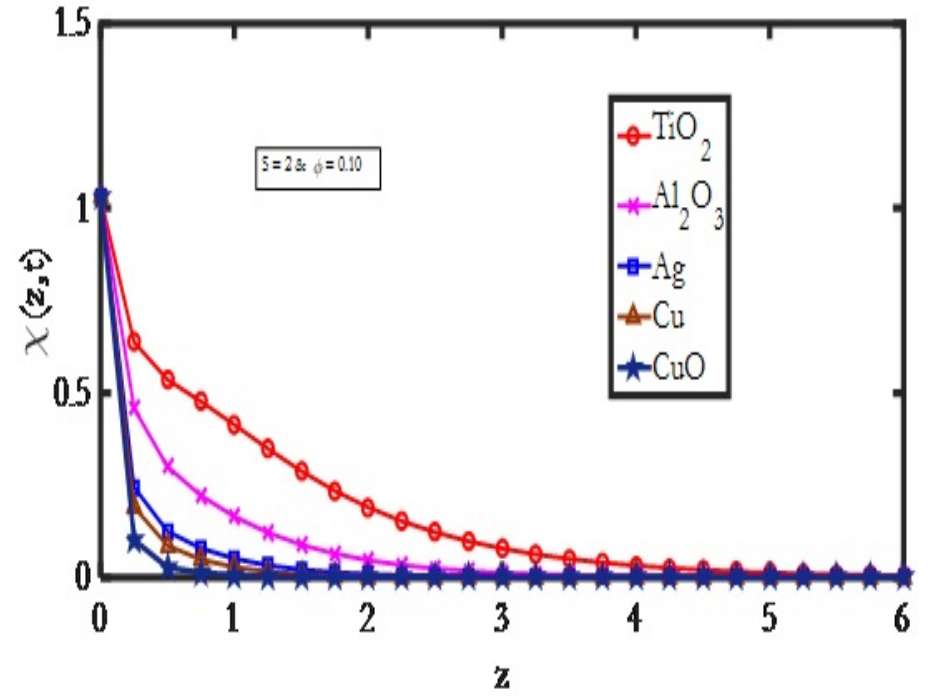

Fig. 5 The effect of Suction Parameter on velocity profiles.

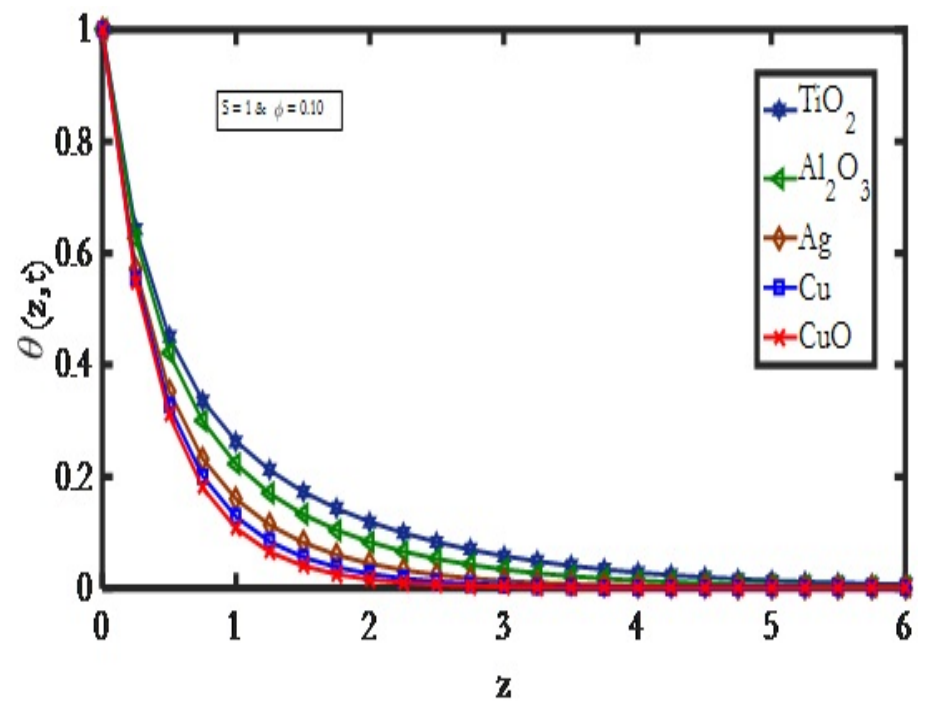

Fig. 6 The effect of Suction Parameter on temperature profiles.

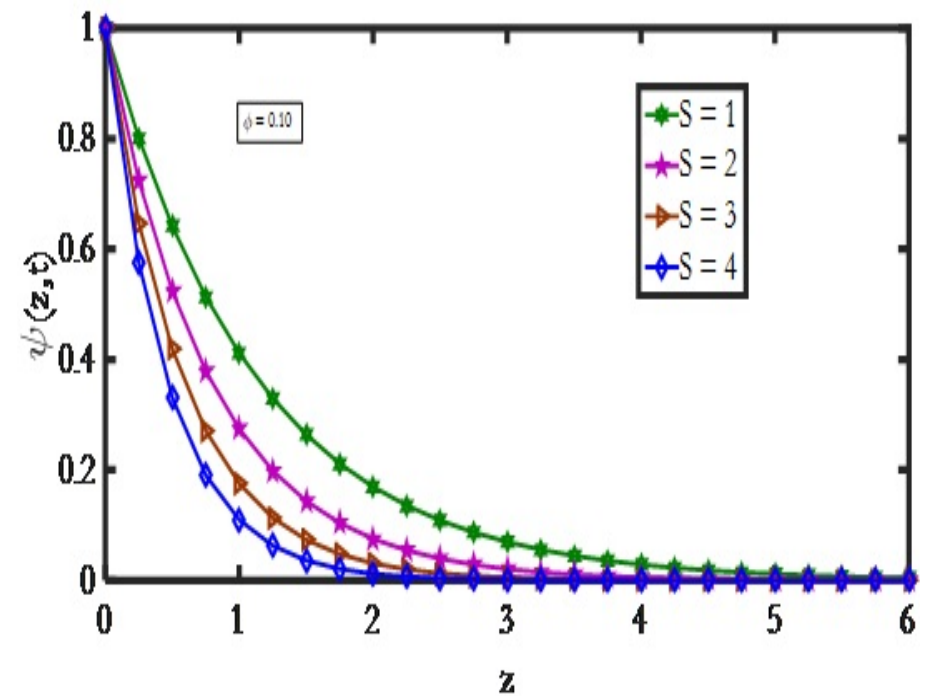

Fig. 7 The effect of Suction Parameter on concentration profiles.

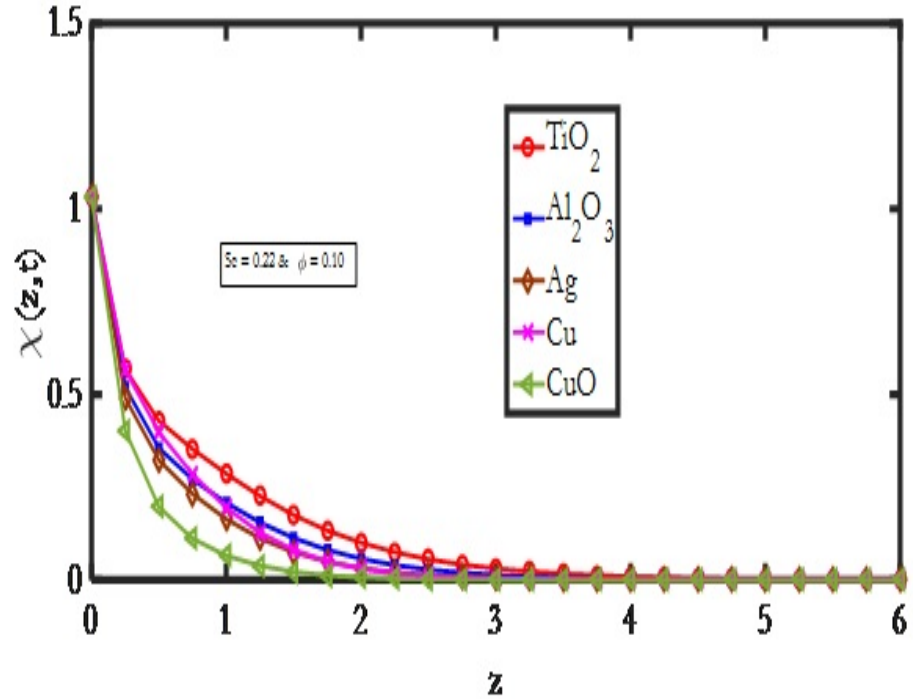

Fig. 8 The effect of Schmidt number on velocity profiles.

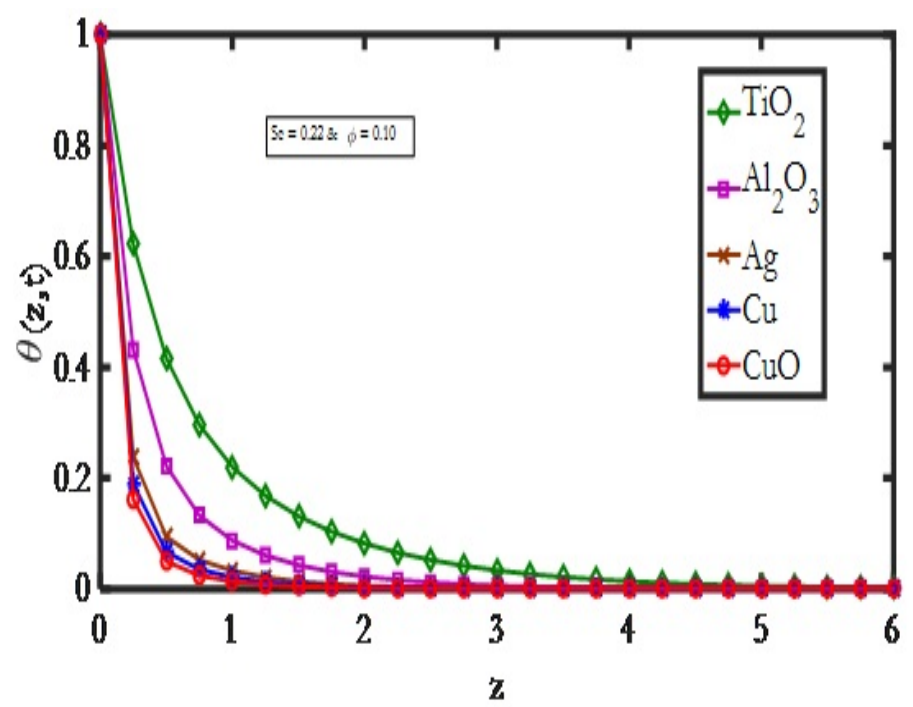

Fig. 9 The effect of Schmidt number on temperature profiles.

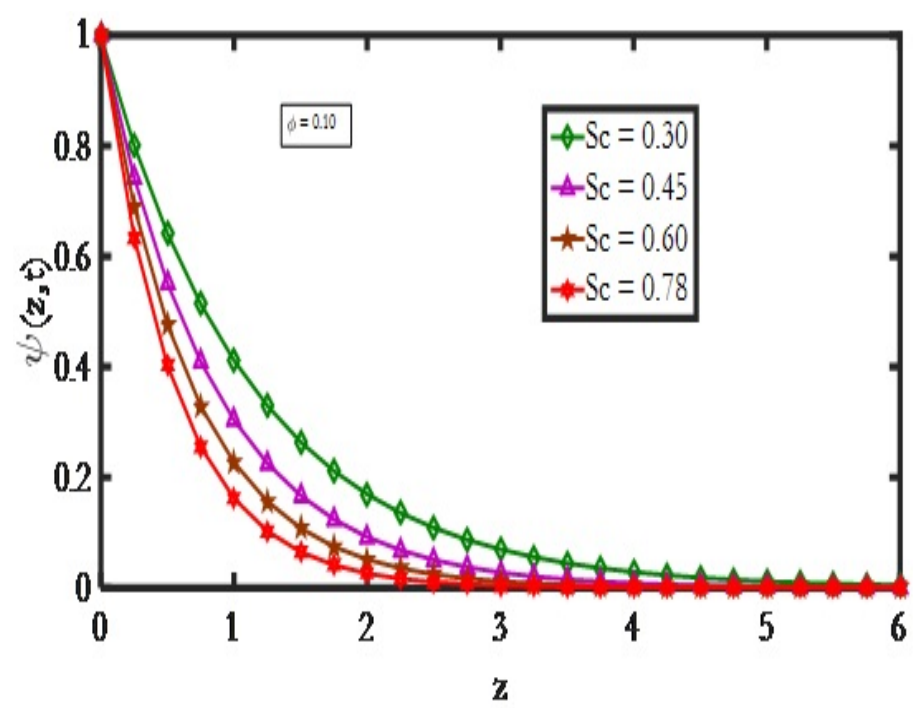

Fig. 10 The effect of Schmidt number on concentration profiles. 


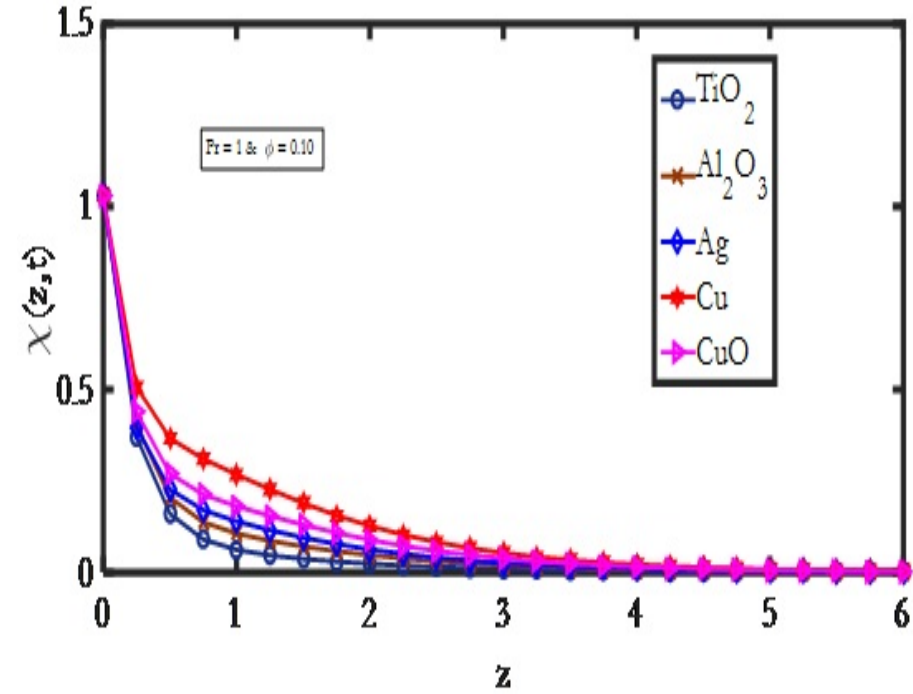

Fig. 11 The effect of Prandtl number on velocity profiles.

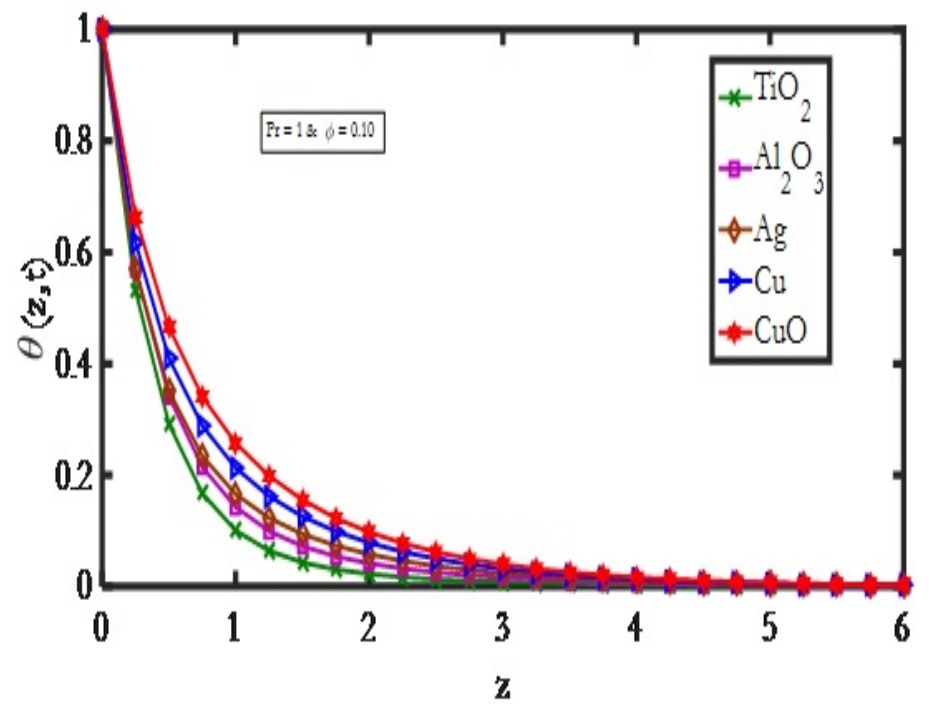

Fig. 12 The effect of Prandtl number on temperature profiles.

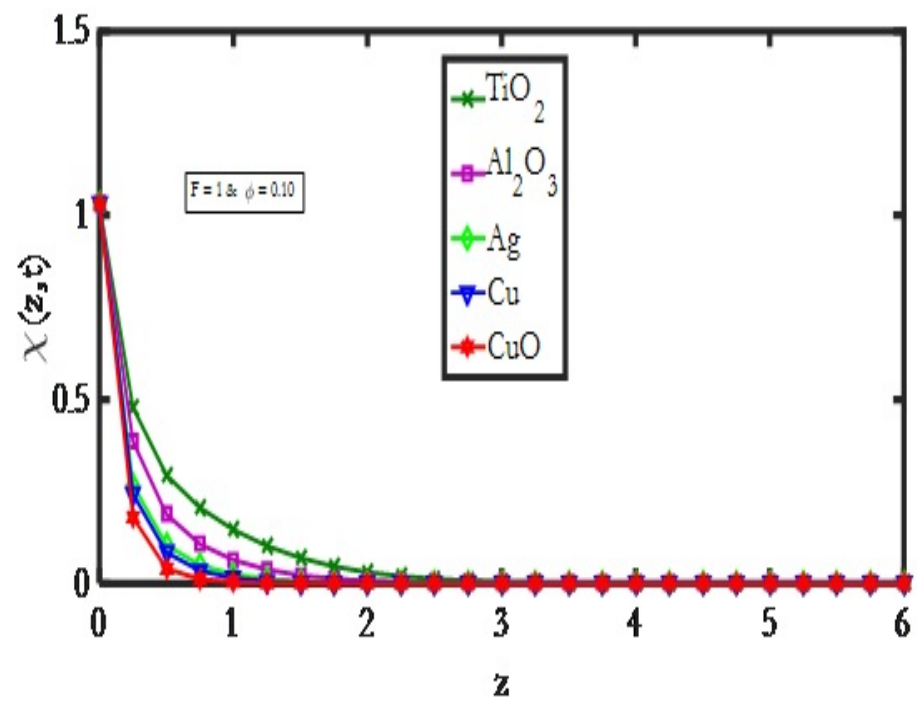

Fig. 13 The effect of Radiation parameter on velocity profiles.

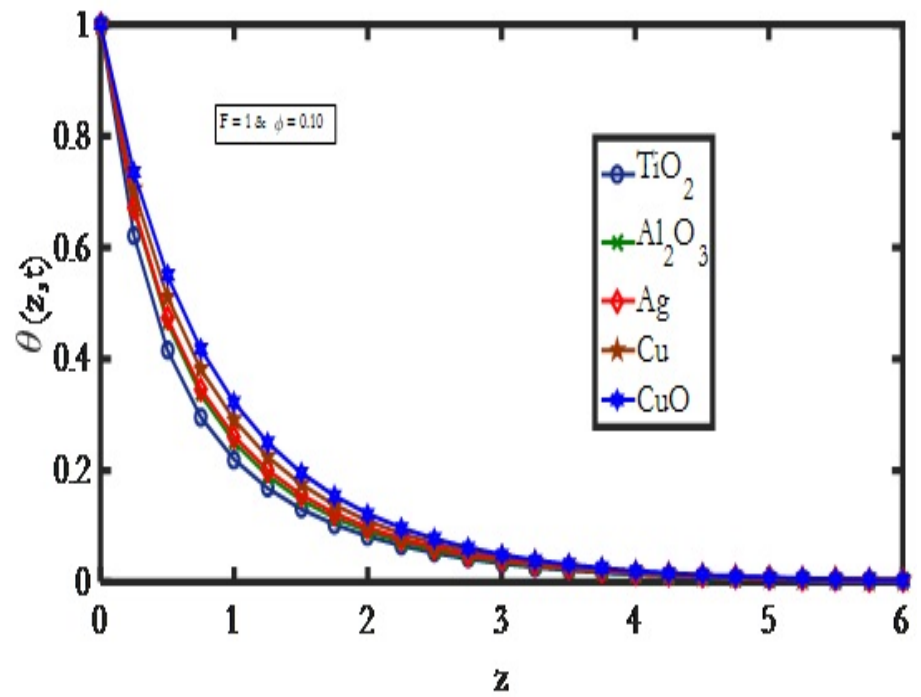

Fig. 14 The effect of Radiation parameter on temperature profiles.

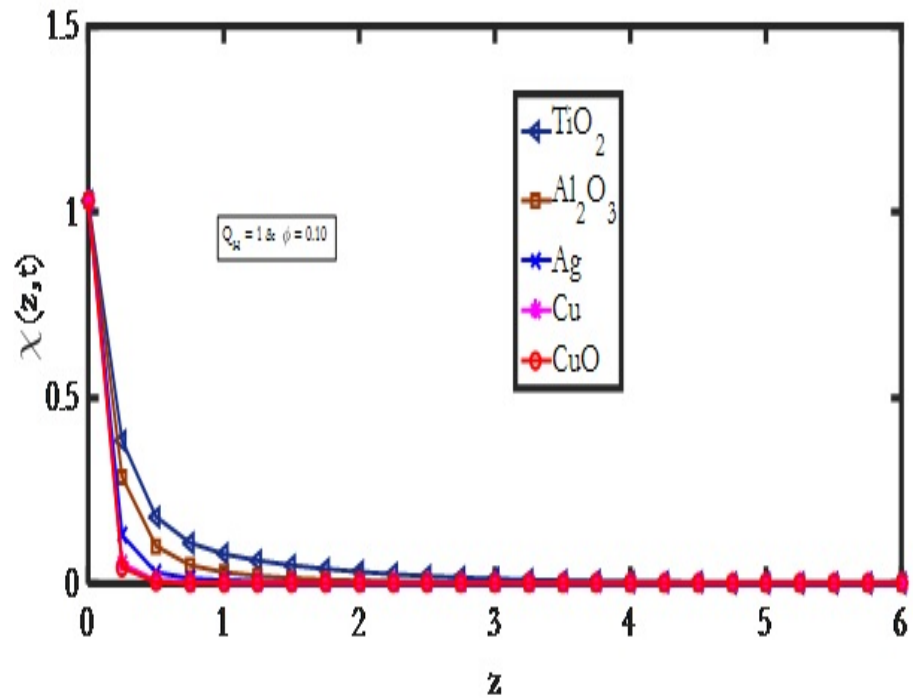

Fig. 15 The effect of Heat Source parameter on velocity profiles.

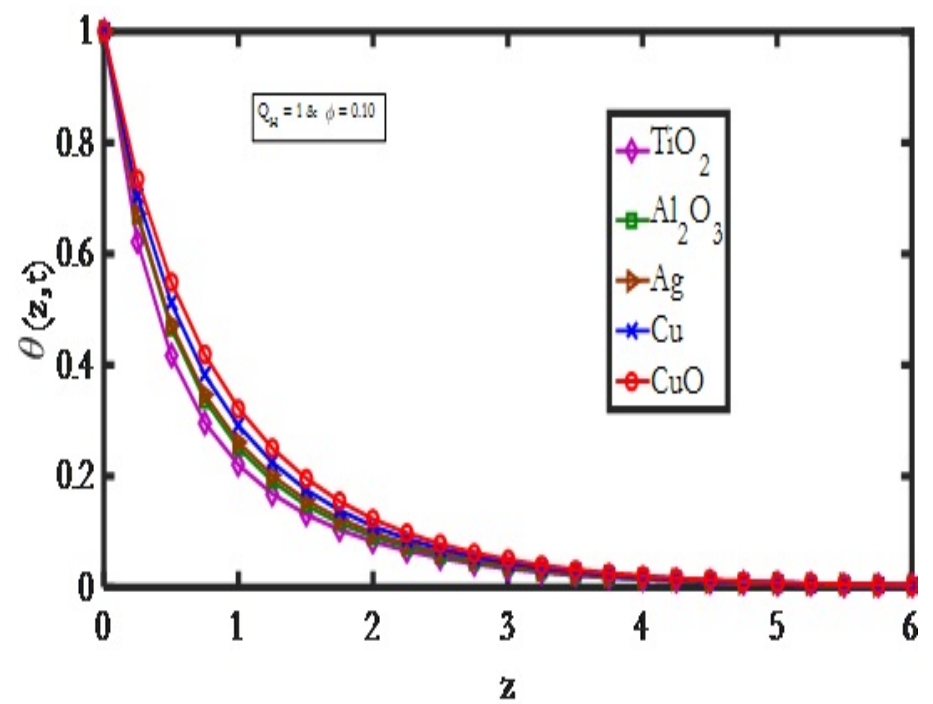

Fig. 16 The effect of Heat Source parameter on temperature profiles. 


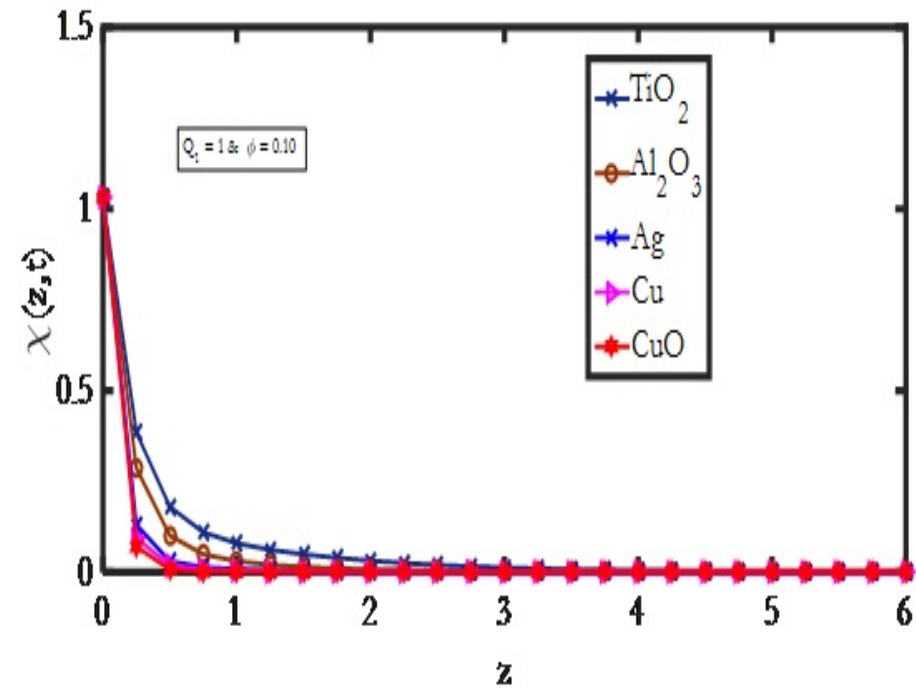

Fig. 17 The effect of Heat Absorption parameter on velocity profiles.

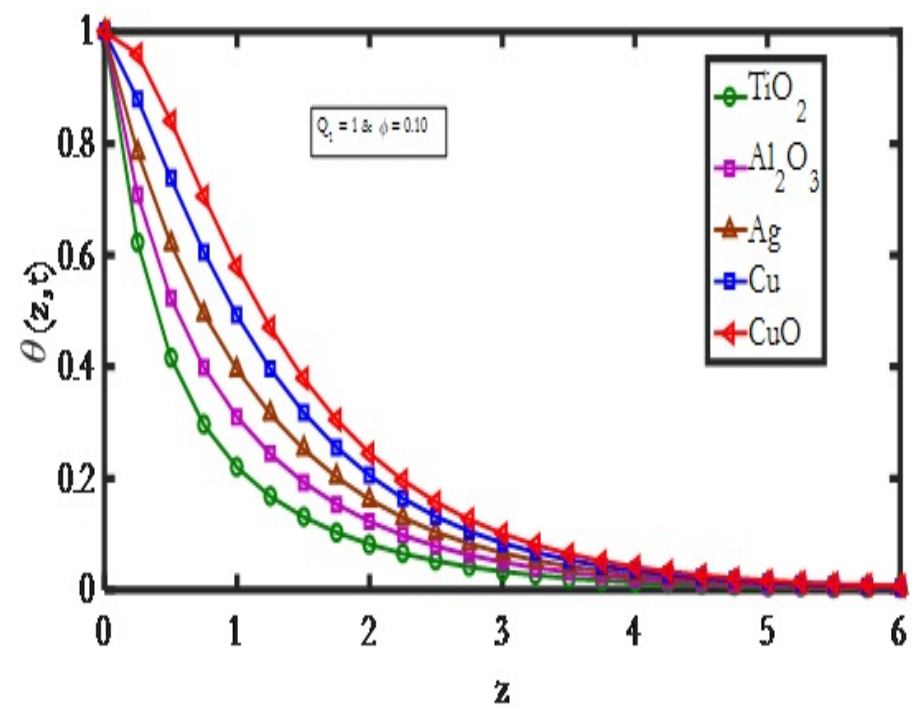

Fig. 18 The effect of Heat Absorption parameter on temperature profiles.

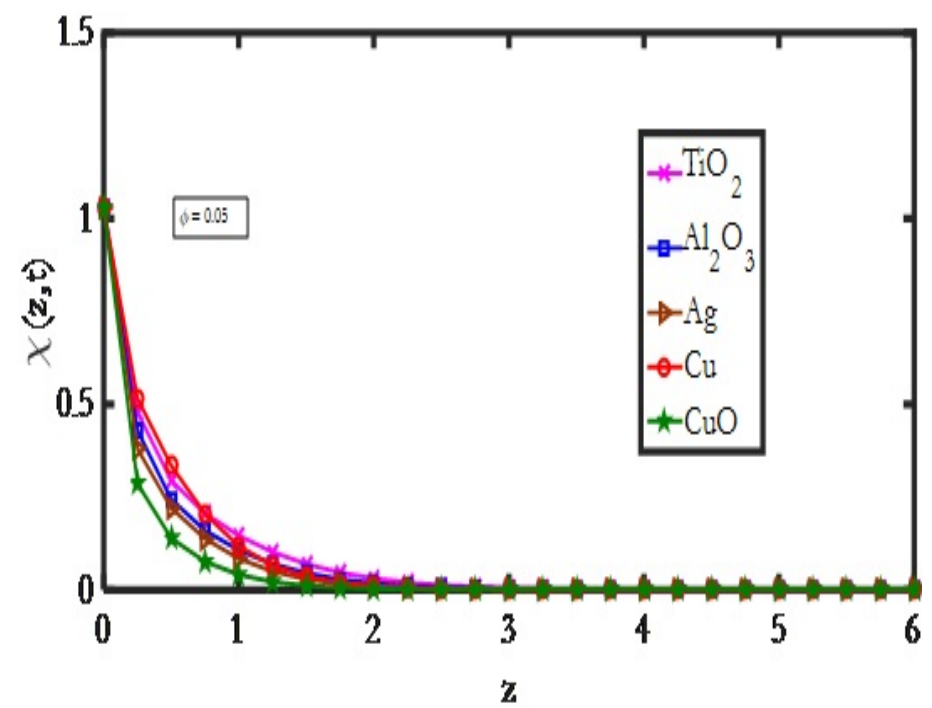

Fig. 19 The effect of volumetric fraction parameter on velocity profiles.

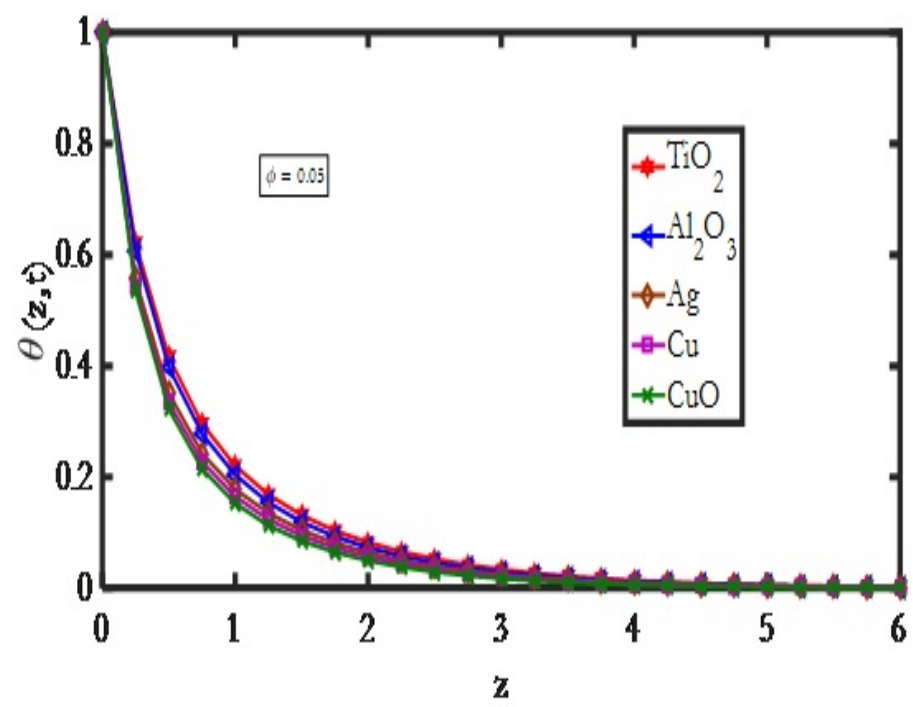

Fig. 20 The effect of volumetric fraction parameter on temperature profiles.

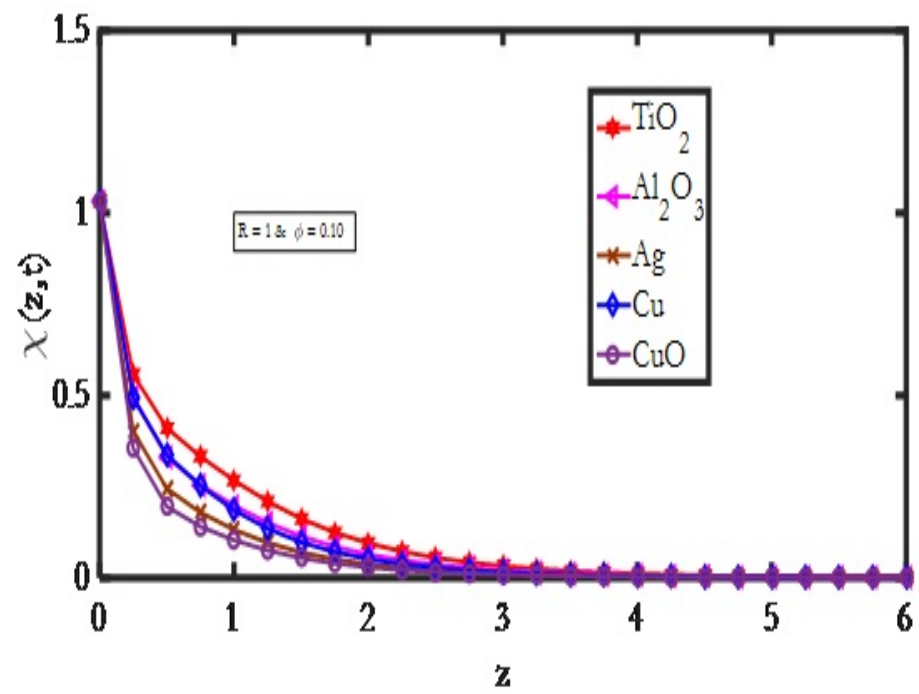

Fig. 21 The effect of rotation parameter on velocity profiles.

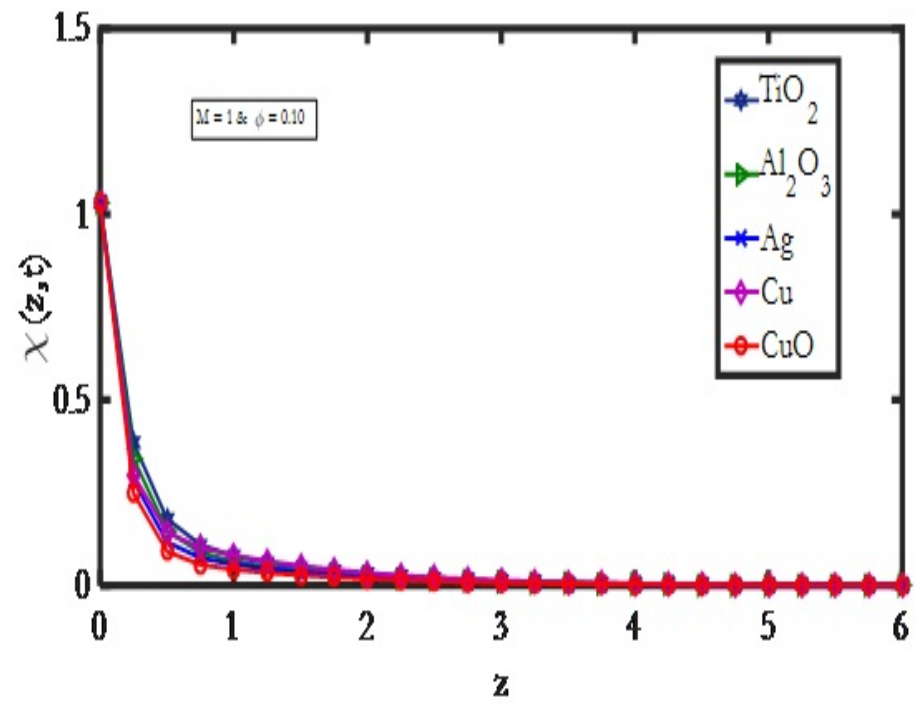

Fig. 22 The effect of Magnetic parameter on velocity profiles. 
shown in Fig. 8. It is noticed the hydro dynamic boundary layer decreases from $\mathrm{TiO}_{2}$ to $\mathrm{CuO}$ nanoparticles. The influence of Schmidt number Sc on the temperature is shown in Fig. 9. It is found that the temperature of the nanofluids decreases from $\mathrm{TiO}_{2}$ to $\mathrm{CuO}$ with an increase in Schmidt number Sc. The influence of Schmidt number Sc on concentration profile is shown in Fig. 10. Concentration decreases with the increase in the Schmidt number indicating that the nanoparticle volume fraction decreases with the increase of Schmidt number. The effects of Prandtl number Pr on the dimensionless velocity is shown in Fig. 11. It is noticed the velocity profiles increases in the order $\mathrm{TiO}_{2}$, $\mathrm{Al}_{2} \mathrm{O}_{3}, \mathrm{Ag}, \mathrm{CuO}$ and $\mathrm{Cu}$. Figure 12 reveals the temperature profiles at prandtl number Pr for five different nanofluids. As prandtl values are increasing, the temperature is also increasing. The figure shows that the temperature is more spread for the nanofluid $\mathrm{TiO}_{2}$. The adjusting feature of nanofluids on the thermal boundary layer thickness is apparent. The effects of radiation parameter $\mathrm{F}$ on the dimensionless velocity is shown in Fig. 13. It is found that the velocity of the fluid decreases from $\mathrm{TiO}_{2}$ to $\mathrm{CuO}$ nanoparticles. Analyzes of radiation parameter $\mathrm{F}$ for five nanofluid are presented in Fig. 14. By increasing $\mathrm{F}$, the temperature increases strongly from $\mathrm{TiO}_{2}$ to $\mathrm{CuO}$ nanoparticles. Figure 15 is sketched to see the influences of heat source parameter. These figures elucidate that the dimension less nanoparticles velocity decreases from $\mathrm{TiO}_{2}$ to $\mathrm{CuO}$ nanoparticles. The effect of heat source Qн on the temperature is depicted in Fig. 16. It is noted that heat source gives an increase in the temperature of the nanofluid and the thermal boundary layer thickness from $\mathrm{TiO}_{2}$ to $\mathrm{CuO}$ nanoparticles. The influences of heat absorption parameter $\mathrm{Q}_{1}$ on the dimensionless velocity is shown in Fig. 17. It is noticed the velocity profiles increases in the order $\mathrm{TiO}_{2}$ to $\mathrm{CuO}$. Figure 18 illustrates the effect of heat absorption on temperature profiles. To comply with the physical intuition, for all the nano fluids, increasing absorption induces the temperature profiles, where as heat generation causes an increase in temperature that is particularly pronounced near the plate. The contribution of nanoparticles volume fraction $\phi$ towards velocity profiles is shown in Fig. 19. Cu-water nanofluid is higher velocity profile that of other nano fluids. Figure 20 presents fluid temperature variations for five types of water based nanofluids effects of volume fraction. The temperature of Cuo-nanofluid is lower than the other nanofluids. When the volume fraction of nanoparticles increases the temperature of the fluid decreases. Figure 21 depicts the effect of rotation parameter $\mathrm{R}$ on the velocity profiles. It is observed that when the rotation parameter $\mathrm{R}$ increases, the nanofluid retards from $\mathrm{TiO}_{2}$ to $\mathrm{CuO}$ nano particles. The influence of magnetic field parameter on velocity is analyzed in Fig. 22. It is found that an increase in magnetic parameter $\mathrm{M}$ leads to reduction of the velocity profiles. The physical meaning of the behavior from Fig. 22 is due to the Lorentz force which results from the presence of a magnetic field in the nanofluid and it works to slow down the velocity. For velocity and temperature profiles all graphs are given due to brevity.

\section{CONCLUSIONS}

The effect of chemical reaction on MHD free convection heat transfer flow of a nanofluid bounded by a semi-infinite flat plate in a rotating frame of reference is theoretically investigated.

- The flow of nanofluid $\mathrm{Cu}$ is very high than the other nanofluids, as $\mathrm{Kr}$ is increasing.

- As chemical reaction parameter is increasing, the temperature is more spread for the nanofluid $\mathrm{TiO}_{2}$.

- The nanofluid concentration of the fluid decelerates with increase in the strength of concentration $\mathrm{Kr}$.

- The velocity of the nanofluid flow decreases with the increase of $\mathrm{S}, \mathrm{Sc}, \mathrm{QH}, \mathrm{F}, \mathrm{R}$ and $\mathrm{M}$ where as increases with $\mathrm{Q}_{1}$ and $\mathrm{Pr}$.

- Boundary layer temperature of nanofluid flow increases with increase of nano particles $\mathrm{Pr}, \mathrm{F}, \mathrm{Q}_{\mathrm{H}}$ and $\mathrm{Q}_{1}$ where as decreases with $\mathrm{S}, \mathrm{Sc}$ and $\phi$.

- Concentration of fluid increases with the increase of S and Sc.

\section{NOMENCLATURE}

$\mathrm{B}_{0}$

$\mathrm{Cp}$

E

g

$\mathrm{J}$

$\mathrm{M}$

n

$\operatorname{Pr}$

$\mathrm{q}_{\mathrm{w}}{ }^{*}$

$\mathrm{Q}$

$\mathrm{QH}_{\mathrm{H}}$

$\mathrm{R}$

$\mathrm{S}$

$\mathrm{t}$

$\mathrm{T}$

Tw

$T_{\infty}$

u, v, w

$\mathrm{U}_{0}$

wo

Greek symbols

$\alpha$

$\beta$

$\varepsilon$

$\phi$

$\kappa$

$\mu$

$\theta$

$\sigma$

$\Omega$

Superscript

*

Subscripts

f $\quad$ Fluid

s Solid

nf Nanofluid $v$

Constant applied magnetic field $\left(\mathrm{Wb} \mathrm{m}^{-2}\right)$

Specific heat at constant pressure $\left(\mathrm{J} \mathrm{kg}^{-1} \mathrm{~K}^{-1}\right)$

Electric field $(\mathrm{kJ})$

Gravity acceleration $\left(\mathrm{m} \mathrm{s}^{-2}\right)$

Current density

Dimensionless magnetic field parameter

Dimensionless frequency

Prandtl number

Dimensional heat flux from the plate

Dimensional heat source $\left(\mathrm{kJ} \mathrm{s}^{-1}\right)$

Dimensionless heat source parameter $\left(\mathrm{kJ} \mathrm{s}^{-1}\right)$

Dimensionless rotation parameter

Dimensionless suction parameter

Dimensionless time (s)

Local temperature of the nanofluid $(\mathrm{K})$

Wall temperature $(\mathrm{K})$

Temperature of the ambient nanofluid $(\mathrm{K})$

Dimensionless velocity components $\left(\mathrm{m} \mathrm{s}^{-1}\right)$

Characteristic velocity $\left(\mathrm{m} \mathrm{s}^{-1}\right)$

Mass flux velocity

Thermal diffusivity $\left(\mathrm{m}^{2} \mathrm{~s}^{-1}\right)$

Thermal expansion coefficient $\left(\mathrm{K}^{-1}\right)$

Dimensionless small quantity $(<<1)$

Solid volume fraction of the nanoparticles

Thermal conductivity $\left(\mathrm{m}^{2} \mathrm{~s}^{-1}\right)$

Dynamic viscosity ( $\mathrm{Pa} \mathrm{s}$ )

Kinematic viscosity $\left(\mathrm{m}^{2} \mathrm{~s}^{-1}\right)$

Dimensionless temperature

Electrical conductivity $\left(\mathrm{m}^{2} \mathrm{~s}^{-1}\right)$

Constant rotation velocity

Dimensional quantities

\section{REFERENCES}

Agarwal, S., Bhadauria, B.S., Siddheshwar, P.G., 2011, "Thermal Instability of a Nanofluid Saturating a Rotating Anisotropic Porous Medium," Special Topics \& Reviews in Porous Media, 2, 53-64.

http://10.1615/SpecialTopicsRevPorousMedia.v2.i1.60

Buongiorno, J., Hu, W., 2005, "Nanofluid Coolants for Advanced Nuclear Power Plants," Proceedings of ICAPP05, Seoul.15-19.

Choi, S.U.S., and Eastman, J.A., 1995, "Enhancing Thermal Conductivity of Fluids with Nanoparticles," Materials Science, 231, 99105.

Ellahi, R., Hassan, M., and Zeeshan, A., 2015, "Study of Natural Convection MHD Nanofluid by Means of Single and Multiwalled Carbon Nanotubes Suspended in a Salt Water Solution", IEEE Transactions on Nanotechnology, 14, 726 - 734.

http://dx.doi.org/10.1109/TNANO.2015.2435899

Ellahi, R., Hassan, M., and Zeeshan, A., 2015, “ Aggregation Effects on Water Base $\mathrm{Al}_{2} \mathrm{O}_{3}$-Nanofluid over Permeable Wedge in Mixed 
Convection", Asia-Pacific Journal of Chemical Engineering , 11, 179186.

http://dx.doi.org/10.1002/apj.1954

Ganapathy. R, 1994, "A Note on Oscillatory Couette Flow in a Rotating System,". ASME J Appl Mech, 61, 208-209.

http://dx.doi.org/10.1115/1.2901403

Hamad, M.A.A., 2011, "Analytical Solution of Natural Convection Flow of a Nanofluid over a Linearly Stretching Sheet in the Presence of Magnetic Field," International Communications in Heat and Mass Transfer, 38, 487-492.

http://dx.doi.org/10.1016/j.icheatmasstransfer.2010.12.042

Hayat, T., Ashraf, M. B., Shehzad, S. A., Alsaedi, A., 2015, "Mixed Convection Flow of Casson Nanofluid over a Stretching Sheet with Convectively Heated Chemical Reaction and Heat Source/Sink," J. Appl Fluid Mechanics, 8, 803-813.

https://doi.org/10.18869/acadpub.jafm.73.238.22995

Kakac, S., Pramuanjaroenkij, A., 2009, "Review of Convective Heat Transfer Enhancement with Nanofluids," International Journal of Heat Mass Transfer, 52, 3187-3196.

http://dx.doi.org/10.1016/j.ijheatmasstransfer.2009.02.006

Kameswaran, P. K. , Narayana, M. , Sibanda, P., Murthy, P. V. S. N., 2012, "Hydromagnetic Nanofluid Flow Due to a Stretching or Shrinking Sheet with Viscous Dissipation and Chemical Reaction Effects," International Journal of Heat and Mass Transfer, 55, 75877595.

http://10.1016/j.ijheatmasstransfer.2012.07.065

Makinde, O.D., Aziz, A., 2011, "Boundary Layer Flow of a Nanofluid Past a Stretching Sheet with a Convective Boundary Condition," Int. J. Therm.Sci., 50, 1326-1332.

https://doi.org/10.1016/j.ijthermalsci.2010.05.005

Malvandi, A., Ganji, D.D., 2014, "Magnetic Field Effect on Nanoparticles Migration and Heat Transfer of Water/Alumina Nanofluid in a Channel", Journal of Magnetism and Magnetic Materials, 362, 172-179.

http://dx.doi.org/10.1016/i.jmmm.2014.03.014

Nadeem, S., Haq, R.U., Akbar, N.S., 2014, "MHD Three-Dimensional Boundary Layer Flow of Casson Nanofluid Past a Linearly Stretching Sheet with Convective Boundary Condition," IEEE Transactions on Nanotechnology, 13, 109-115.

https://doi.org/10.1109/TNANO.2013.2293735

Noreen Sher Akbar., Raza, M., and Ellahi, R., 2015 "Impulsion of Induced Magnetic Field for Brownian Motion of Nanoparticles in Peristalsis", Applied Nanoscience, 6, 359-370.

http://dx.doi.org/10.1007/s13204-015-0447-1

Oztop HF, Abu-Nada E (2008), "Numerical Study of Natural Convection in Partially Heated Rectangular Enclosures Filled with Nanofluids". Int J Heat Mass Transf 29,1326-1336.

doi:10.1016/j.ijheatfluidflow.2008.04.009

Raju, C.S.K. and Sandeep, N., 2016, "Heat and Mass Transfer in MHD Non-Newtonian Bio-Convection Flow over a Rotating Cone/Plate with Cross Diffusion," Journal of Molecular Liquids, 215, 115-126. http://dx.doi.org/10.1016/j.molliq.2015.12.058

Ramana Reddy, J.V., Sugunamma, V., Sandeep, N. , 2017, "Effect Of Frictional Heating on Radiative Ferrofluid Flow over a Slendering stretching Sheet with Aligned Magnetic Field," Europen Physical Journal Plus, 132:7

http://doi:10.1140/epjp/i2017-11287-1

Rashidi, M.M., Basiriparsa, A., Shamekhi, L., and Momoniat, E., 2015, "Entropy Generation Analysis of the Revised Cheng-Minkowycz Problem for Natural Convective Boundary Layer Flow of Nanofluid in a Porous Medium," Thermal Science, 19, 169-178.

http://dx.doi.org/10.2298/TSCI15S1S69R

Rashidi, M.M., Momoniat, E., Ferdows, M., and Basiriparsa, A., 2014 "Lie Group Solution for Free Convective Flow of a Nanofluid Past a Chemically Reacting Horizontal Plate in a Porous Media," Math. Prob. Engin., 2014, 21

http://dx.doi.org/10.1155/2014/239082

Rashidi, M. M., Vishnu Ganesh, N., Abdul Hakeem, A.K., Ganga, B., 2014, "Buoyancy Effect on MHD Flow of Nanofluid Over a Stretching Sheet in the Presence of Thermal Radiation", Journal of Molecular Liquids, 198, 234-238.

http://dx.doi.org/10.1016/j.molliq.2014.06.037

Rushi Kumar, B., Sravan Kumar, T., Vijaya Kumar, A. G., 2015, "Thermal Diffusion and Radiation Effects on Unsteady Free Convection Flow in the Presence of Magnetic Field Fixed Relative to the Fluid or to the Plate," Journal of Frontiers in Heat and Mass Transfer, 6, 6-12.

http://dx.doi.org/10.5098/hmt.6.12

Sandeep, N., 2016, "Effect of Aligned Magnetic Field on Liquid Thin Film Flow of Magnetic-Nanofluid Embedded with Graphene Nanoparticles," Advanced Powder Technology, (in Press).

http://dx.doi.org/10.1016/j.apt.2016.12.012

Satyanarayana, P.V., Venkateswarlu, B., Venkataramana, S., 2013, "Effects of Hall Current and Radiation Absorption on MHD Micropolar Fluid in a Rotating System," Ain-Shams Engineering Journal, 4, 843-854.

http://dx.doi.org/10.1016/j.asej.2013.02.002

Sheikholeslami, M., Ganji, D. D., 2014, "Unsteady Nanofluid Flow and Heat Transfer in Presence of Magnetic Field Considering Thermal Radiation," Journal of the Brazilian Society of Mechanical Sciences and Engineering, 37, 895 - 902.

http://dx.doi.org/10.1007/s40430-014-0228-x

Sheikholeslami, M., Bandpy, M. G., Ellahi, R., Zeeshan, A.2014, "Simulation of MHD CuO-Water Nanofluid Flow and Convective Heat Transfer Considering Lorentz Forces", Journal of Magnetism and Magnetic Materials, 369, 69-80.

http://dx.doi.org/10.1016/j.jmmm.2014.06.017

Tawade, J., Abel, M.S., Metri, P.G. and Koti, A., 2016, "Thin Film Flow and Heat Transfer over an Unsteady Stretching Sheet with Thermal Radiation, Internal Heating In Presence of External Magnetic Field," Int. Adv. Appl. Math. And Mech., 3, 29-40.

https://arxiv.org/abs/1603.03664

Turkyilmanzoglu. M.,2016, "Natural Convective Flow of Fluids Past a Radiative and Impulsive Vertical Plate”. J. Aerosp. Eng.,,29, 1-8. https://doi.org/10.1061/(ASCE)AS.1943-5525.0000643

Xie, H. W. Y., Wei, C., 2010, "MgO Nanofluids: Higher Thermal Conductivity and Lower Viscosity among Ethylene Glycol-based Nanofluids Containing Oxide Nanoparticles," Journal of Experimental Nanoscience, 5, 463-472.

http://dx.doi.org/10.1080/17458081003628949 